\title{
EDITORIAL
}

\section{Acute leukaemia in adults: researching the patient's perspective}

Leukemia (2006) 20, 206-207. doi:10.1038/sj.leu.2404005;

published online 3 November 2005

'... then you really! think, so now you're in your early thirties, built a house, lived in it for just two years and then, you actually wanted to get married, have a child and everything, and then, something like this! comes along, then you ask yourself (interviewer: hm?) whether one was doing too well, so to speak, or whether one has done anything (interviewer: hm) or what one has done wrong (interviewer: hm?) or what, what could! have been the reason, that it hit you!' (34 years old male patient with thymic T-ALL, two weeks after notification of the diagnosis).

\section{Dealing with an existential crisis}

The diagnosis of acute leukaemia presents a sudden vital threat for the patient, an attack to his very existence. Since the term leukaemia is generally associated with mortality and since patients are nowadays informed about their disease by their treating haematologist, the confrontation with this diagnosis means an overwhelming experience right from the first moment.

Owing to the nature of the disease, treatment usually starts within one or two days after the diagnosis of acute leukaemia. During this narrow timeframe, the situation has to be explained to the patient and he or she has to consent to the remaining diagnostic procedures and especially to the initiation of chemotherapy. Not much time is left for reflections about life and death; rather a race starts to escape the area of danger. However, during the following days and weeks, while on treatment, the mortality of the disease remains and time will usually allow, if not force, the recognition of some existential questions.

Many relevant medical topics are usually discussed with the patient, however, do we allow him or her to deal with the emerging fundamental aspects of his suffering? Talking about the disease by itself will enable the patient to escape the primary state of speechlessness. Talking is a first means to counteract the threat of the disease by the use of terms or by the articulation of feelings and it is a way to relate to another person in this difficult situation. These are elementary needs. The question is whether we are ready to meet these needs and whether we know what to ask and what to say. Do we understand the emotional situation of a patient diagnosed with acute leukaemia?

\section{Relevant questions}

While questions regarding quality of life have been asked in adult patients with acute leukaemia, there are other burning issues. When facing mortality due to this disease, how does the patient really feel and what are his or her thoughts? How much information can and should reasonably be given before starting chemotherapy? Is there a plan for the subsequent delivery of information or for follow-up talks? What kind of messages beside medical information does the individual patient need?
Do we understand enough of the patient's personality and reaction in order to ensure optimal cooperation and compliance? What is the patient's comprehension of the disease? Which individual disease theories and coping strategies can be recognized? What are his or her own resources emotionally, intellectually and spiritually? What are the patient's hope and confidence based upon? Are there ideas that should be either strengthened and supported or rather corrected? As can be seen, the need for comprehension lies on both sides; for the patient to understand the disease, and for the physician to understand the patient.

\section{Researching the patient's perspective}

Answering the questions raised above is not a trivial matter despite their apparently basic character. Some prefer an intuitive or spontaneous approach to these problems, but this may possibly not be sufficient for the patient and it will certainly not allow the spread of experience to the medical and scientific community. Rather, as the result of a deliberate effort, the gathering of knowledge will enable us to comprehend our patients, and the acquisition of communicative and interventional skills will be necessary on this way. ${ }^{1}$

Psycho-oncological research topics in adult patients with acute leukaemia cover quality of life, ${ }^{2,3}$ fatigue, ${ }^{4}$ the evaluation of anxiety, depression ${ }^{5}$ and cognitive function. Several studies have analysed psychological distress in the context of haematopoetic stem cell transplantation. ${ }^{6-10}$ So far, little is known about illness perception, causal attributions, subjective comprehension of the disease and about coping strategies in patients with acute leukaemia. A blind spot in the research of psychosocial aspects of adult patients with acute leukaemia is the process evaluation of the patient's perspective during the period of chemotherapy.

Methodologically, most studies use quantitative techniques and apply questionnaires with scaled answering possibilities (e.g. EORTC QLQ-C30, QSC-R23) in order to study the topics mentioned above. This approach is appropriate if a set of relevant, well-defined questions is asked. Limitations of quantitative methods are that only known variables are examined and that only rateable answers are possible. Moreover, there is a risk for the researcher to ask questions, which may be less relevant to the patient.

The analysis of the complex experiences of suffering and of the patient's views and emotions when facing mortality, however, requires a sophisticated approach. The finding of new and unexpected results requires that the patient has the chance to freely communicate and to openly describe his thoughts and feelings. Valuable sources are narrative interviews or semi-structured interviews. The text material can subsequently be subjected to qualitative research analysis methods. This includes a verbatim transcription of the record, followed by condensation or partial abstraction of the content according to specific rules. Subsequently, fragments of the content can be grouped into categories which are either predefined or created in interaction with the text in order to allow interindividual or, in 
the case of a longitudinal study, intraindividual follow-up comparison. This type of analysis is a cyclical process. It involves different analysis stages, dropping a category or a code if a more useful one is emerging. Finally, a complex category system emerges. In further steps of abstraction the method of empirically grounded type construction is helpful. Ideal types are analytical constructs involving an accentuation of typical courses of conduct. They serve the investigator as a reference which allows to ascertain similarities and deviations in concrete cases. $^{11-15}$

Qualitative analysis has been rarely applied to haematologic diseases. ${ }^{6,16,17}$ We have conducted an in-depth analysis of interviews with adults patients suffering from acute leukaemia at different time points asking for illness perception, lay theories, and coping strategies. Among other results ${ }^{18,19}$ we describe the existential crisis after notification of the disease, the effect of age on coping mechanisms, and important aspects of trust. These results have the potential to improve our understanding of and our approach to the patients, the training of young colleges and they allow to shape the character of psycho-oncological interventions. Since a high degree of methodological expertise is required for this kind of analysis, we recommend a collaboration between haematologists and academic experts in the field of psychology, psychosomatic medicine or psychotherapy.

While research-oriented approaches will teach us the perspective of patients with acute leukaemia, the daily need to serve the haematological and oncological patient psychologically should not be overlooked. At our institution, evaluation of scores for anxiety, depression and self-efficacy have become part of the psychological standard assessment. The results help the psychologist to guide the patient and to anticipate the eventual need for interventions. Furthermore, the data provided by the psychologist represent an optimal possibility for the treating physicians to learn general psychodynamic aspects and to understand the affective or verbal reactions of the patient.

\section{Conclusion}

Despite some recognition of the psychological distress caused by the diagnosis of acute leukaemia in adult patients, the experience of the ensuing existential crisis, its course as well as strategies to overcome the challenge of the situation have hardly been analysed. Psycho-oncology can and should cover different techniques and modalities. Increasing our understanding of the patient will improve the interaction with the patient, improve his or her compliance during difficult periods of the treatment and teach us deeper lessons about life during situations of vital threat.

\section{Acknowledgements}

The work of our study group is supported by the German José Carreras Leukemia Foundation (Grant Number DJCLS-R03/22p).

M Koenigsmann ${ }^{1}$, M Koehler ${ }^{1}$, A Franke ${ }^{1}$, J Frommer ${ }^{2}$ ${ }^{1}$ Department of Haematology/Oncology, Medical Faculty of the Otto-von-Guericke-University, Magdeburg, Germany and ${ }^{2}$ Department of Psychosomatic Medicine and Psychotherapy,
Medical Faculty of the Otto-von-Guericke-University, Magdeburg, Germany

E-mail: michael.koenigsmann@medizin.uni-magdeburg.de

\section{References}

1 Fallowfield L, Jenkins V. Communicating sad, bad, and difficult news in medicine. Lancet 2004; 363: 312-319.

2 Schumacher A, Kessler T, Buchner T, Wewers D, van de Loo J. Quality of life in adult patients with acute myeloid leukemia receiving intensive and prolonged chemotherapy - a longitudinal study. Leukemia 1998; 12: 586-592.

3 Redaelli A, Stephens JM, Brandt S, Botteman MF, Pashos CL. Shortand long-term effects of acute myeloid leukemia on patient healthrelated quality of life. Cancer Treat Rev 2004; 30: 103-117.

4 Schumacher A, Wewers D, Heinicke A, Sauerland C, Koch OM, van de Loo $\mathrm{J}$ et al. Fatigue as an important aspect of quality of life in patients with acute myeloid leukemia. Leuk Res 2002; 26: 355-362.

5 Montgomery C, Pocock M, Titley K, Lloyd K. Predicting psychological distress in patients with leukaemia and lymphoma. J Psychosom Res 2003; 54: 289-292.

6 Tschuschke V, Hertenstein B, Arnold B, Bunjes D, Denzinger R, Kaechele $\mathrm{H}$. Associations between coping and survival time of adult leukemia patients receiving allogeneic bone marrow transplantation: results of a prospective study. J Psychosom Res 2001; 50: 277-287.

7 Trask PC, Paterson AG, Riba M, Brines B, Griffith K, Parker P et al. Assessment of psychological distress in prospective bone marrow transplant patients. Bone Marrow Transplantation 2002; 29: 917-925.

8 Gruber U, Fegg M, Buchmann M, Kolb HJ, Hiddemann W. The long-term psychosocial effects of haematopoetic stem cell transplantation. Europ J Cancer Care 2003; 12: 249-256.

9 Hoodin F, Kalbfleisch KR, Thornton J, Ratanatharathorn V. Psychosocial influences on 305 adults' survival after bone marrow transplantation: Depression, smoking, and behavioral self-regulation. J Psychosomat Res 2004; 57: 145-154.

10 Andrykowski MA, Bishop MM, Hahn EA, Cella DF, Beaumont JL, Brady MJ et al. Long-term health-related quality of life, growth, and spiritual well-being after hematopoietic stem-cell transplantation. J Clin Oncol 2005; 23: 599-608.

11 Strauss A, Corbin J. Basics of qualitative research: techniques and procedures for developing grounded theory, 2nd edn. Sage: Thousand Oaks London New Delhi, 1998, 73-85.

12 Elliot R, Fischer C, Rennie D. Evolving guidelines for the publication of qualitative research in psychology and related fields. Br J Clinical Psycho 1999; 38: 215-229.

13 Frommer J. Qualitative research in diagnostic processes. Psychopathology 1999; 32: 121-126.

14 Malterud K. The art and science of clinical knowledge: evidence beyond measures and numbers. Lancet 2001; 358: 397-400.

15 Malterud K. Qualitative research: standards, challenges, and guidelines. Lancet 2001; 358: 483-488.

16 Berterö C, Eriksson BE, Ek AC. Explaining different profiles in quality of life experiences in acute and chronic leukemia. Cancer Nursing 1997; 20: 100-104.

17 Friis LS, Elverdam B, Schmidt KG. The patient's perspective - a qualitative study of acute myeloid leukemia patients' need for information and their information-seeking behaviour. Support Care Cancer 2003; 11: 162-170.

18 Koenigsmann M, Koehler K, Regner A, Kreuzman N, Franke A, Frommer J. Subjective theories of illness in patients with acute myeloid and lymphatic leukemia. Onkologie 2004; 27 (S3): 155.

19 Kochler K, Reghet A, Koenigsmann M, Franke A, Frommer J. Illness perceptions of patients suffering from acute leukemia one week after diagnosis. Z Psychosom Med Psychother, (in press). 